\title{
CONTRIBUIÇÕES DA EDUCAÇÃO PROFISSIONAL EM SAÚDE À FORMAÇÃO PARA O TRABALHO EM CLASSES HOSPITALARES*
}

\author{
Alessandra Santana Soares e Barros ${ }^{* *}$
}

\begin{abstract}
RESUMO: Neste artigo discute-se a capacitação de pedagogos e professores para o trabalho em classes hospitalares a partir da reafirmação do caráter multidisciplinar do campo do conhecimento, de onde emanam as práticas e saberes necessários à formação qualificada destes profissionais. Nesta perspectiva, a proposta apresentada aponta, em especial, a grande proximidade existente entre os desafios da formação de pessoal técnico e de nível médio do setor de saúde e aquele da formação de professores para classes hospitalares. A contribuição específica e inovadora deste artigo está, ainda, na sugestão de uma estratégia de ensino-aprendizagem baseada na utilização de narrativas literárias sobre saúde e doença - as chamadas Narrativas em Medicina. As propostas aqui sugeridas não estão detalhadas operacionalmente. Diga-se, também, que foram pensadas para atender a demandas de educação profissional continuada, ou seja, se prestariam prioritariamente a professoras em serviço, o que não impede, contudo, suas adaptações para os contextos dos cursos superiores de Pedagogia e Licenciaturas.
\end{abstract}

Palavras-chave: Classe hospitalar. Educação profissional em saúde. Currículo. Pedagogia.

\section{CONTRIBUTIONS FROM PROFESSIONAL HEALTH EDUCATION TO TEACHERS' PREPARATION FOR WORK AT HOSPITAL SCHOOLS}

ABSTRACT: This paper fosters a discussion on the qualification of pedagogues and teachers for teaching ill children at hospitals. The discussion springs from the assurance of interdisciplinarity in that

\footnotetext{
* Este trabalho foi desenvolvido no contexto das atividades de pesquisa de projeto financiado pelo CNPq.

** Doutora em Antropologia, professora adjunta da Faculdade de Educação da Universidade Federal da Bahia (UFBA) e coordenadora do Centro de Estudos sobre Recreação, Escolarização e Lazer em Enfermarias Pediátricas (www.cerelepe.faced.ufba.br).E-mail: alssb@ufba.br
} 
Contribuições da educação profissional em saúde à formação para o trabalho...

field, which is the source of knowledgement and practices necessary for the education of the above professionals. With this perspective, we point out to the close similarity between the challenges of educating individuals to be technical and undergraduate health workers and to be hospital class teachers. The specific and innovative contribution of this paper lies in suggesting a teaching and learning strategy based on storytelling about health and illness - the so-called Narratives on Medicine. The operational use of this suggestion is not detailed in this article. Besides, the suggestions are meant to answer the demands of continuous professional education, which means they are useful mostly for preparing teachers already at work. Nevertheless, that does not mean that they cannot be adapted for pedagogy and licentiateship courses.

Key words: Hospital school. Professional health education. Curriculum. Pedagogy.

\section{Introdução: revendo princípios e conceitos sobre a classe hospitalar}

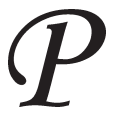
ara se alcançar o significado do sofrimento que se pode experimentar na hospitalização, independentemente daquele relativo à dor e à doença em si, os apontamentos sócio-antropológicos de Goffman (2007) contribuem para as reflexões sobre o que ele chamou de instituiçôes totais. Ao definir e interpretar a instituição hospitalar como uma instituição total, Goffman nos diz:

Uma disposição básica da sociedade moderna é que o indivíduo tende a dormir, brincar e trabalhar em diferentes lugares, com diferentes co-participantes, sob diferentes autoridades e sem um plano racional geral. $\mathrm{O}$ aspecto central das instituiçôes totais pode ser descrito com a ruptura das barreiras que comumente separam essas três esferas da vida. Em primeiro lugar, todos os aspectos da vida são realizados no mesmo local e sob uma única autoridade. Em segundo lugar, cada fase da atividade diária do participante é realizada na companhia imediata de um grupo relativamente grande de outras pessoas, todas elas tratadas da mesma forma e obrigadas a fazer as mesmas coisas em conjunto. Em terceiro lugar, todas as atividades diárias são rigorosamente estabelecidas em horários, pois uma atividade leva, em tempo predeterminado, à seguinte, e toda a seqüência de atividades é imposta de cima, por um sistema de regras formais explícitas e um grupo de funcionários. Finalmente, as várias atividades obrigatórias são reunidas num plano racional, supostamente planejado para atender aos objetivos oficiais da instituição. (2007, p. 17-18) 
A classe hospitalar ${ }^{1}$ surge, então, como uma modalidade de atendimento prestado a crianças e adolescentes internados em hospitais e parte do reconhecimento de que esses jovens pacientes, uma vez afastados da rotina acadêmica e privados da convivência em comunidade, vivem sob risco de fracasso escolar e de possíveis transtornos ao desenvolvimento.

Por isso, nos termos da política de educação especial, da política de inclusão ou da política de atenção à diversidade do Ministério da Educação, crianças e adolescentes hospitalizados são portadores de necessidades especiais. Nos termos da política de humanização do Ministério da Saúde, os pacientes pediátricos são alvos preferenciais, uma vez que são mais susceptíveis aos problemas resultantes da baixa qualidade dos serviços prestados, bem como da despersonalização e do distanciamento afetivo, característicos da assistência hospitalar.

Em grande medida, essas políticas referendam práticas já consagradas em países europeus, cujas primeiras iniciativas remontam ao período posterior à Primeira Guerra. Provêm dessas experiências reflexões que se atualizaram nos seguintes termos:

Uma escola no hospital permite à criança doente conservar os laços com sua vida anterior à internação. É um lugar neutro, resultado de um projeto de futuro, pois a criança, depois de sua hospitalização, retomará sua vida normal de criança. A classe agrupa crianças de idades diferentes: o professor desenvolve com elas uma pedagogia tendo em conta ao mesmo tempo a capacidade psíquica das crianças doentes e seus diferentes níveis de escolaridade. (Reiner-Rosenberg, 2003, p. 21)

Assim, tendo em vista a dimensão e importância de uma modalidade de atenção que privilegiasse o desenvolvimento biopsicossocial de crianças e adolescentes em circunstâncias de morbidade e exclusão, a Resolução n. 41/95, do Conselho Nacional dos Direitos da Criança e do Adolescente, garantiu para esta parcela da população, o "direito a desfrutar de alguma forma de recreação, programas de educação para a saúde e acompanhamento do currículo escolar, durante sua permanência hospitalar" (Brasil, 1995).

Uma das diretrizes para o funcionamento adequado desta Resolução é, portanto, o acompanhamento do currículo escolar. Para tanto, quando a criança ou adolescente hospitalizado já freqüentava uma escola antes da internação, a classe hospitalar deve buscar contato com a 
Contribuições da educação profissional em saúde à formação para o trabalho...

escola para que as atividades, então empreendidas, correspondam em continuidade. Se não for possível contatar a escola, são utilizados materiais didáticos disponibilizados pela própria classe hospitalar e os professores destas devem favorecer ao aluno o aprendizado dos conteúdos da série que lhe correspondam. Mesmo que a criança ou adolescente não esteja freqüentando a escola regularmente, é promovida a aprendizagem de competências próprias para os seus estágios de desenvolvimento intelectual.

Aquilo que poderia ser chamado de turma, numa enfermaria pediátrica, trata-se de um grupo aberto e de estrutura dinâmica. Assim, entram e saem crianças e adolescentes com relativa freqüência. Desse modo, a constituição da classe hospitalar é sempre variável ao longo de um período. Para cada jovem paciente o tempo de permanência no hospital é diferente e, por conseguinte, a duração, extensão e natureza do investimento pedagógico/terapêutico recebido também. O perfil do grupo é igualmente variável, no sentido de que os pacientes são diferentes também em suas demandas acadêmicas, além do que têm origens socioeconômicas diversas. A classe hospitalar é, assim, uma "turma" multisseriada. Além disso, embora se valha da denominação "classe", essa modalidade de atendimento não precisa estar reduzida à utilização de um espaço físico circunscrito. Algumas, de fato, o têm. Mas, em outras, pode-se utilizar a biblioteca do hospital, o refeitório em horários ociosos, as varandas da enfermaria e mesmo os leitos, sob os quais se debruçam professores em atendimentos individuais. Passeios externos com as crianças, como idas a parques, cinemas, teatro, praia, feiras de livros e outros lugares, também configuram atendimentos na forma de classe hospitalar. Esses aspectos são descritos por Barros (1999).

A qualidade da atenção dirigida aos jovens pacientes, quase que individualizada, acompanhada muito proximamente e, muitas vezes, dado o curto tempo de permanência, centrada no alcance de objetivos de curto prazo, imprime ao trabalho da classe hospitalar a característica paralela de atuação intensiva para a superação de dificuldades de aprendizagem. Estatísticas sobre evasão, repetência e defasagem na relação idade x série, ou rankings de desempenho acadêmico como o SAEB ou o Prova Brasil são indicadores de que, em alguns estados do Brasil, situações de exclusão ou iminência de fracasso escolar se impõem para crianças e adolescentes, independentemente de condiçōes extraordinárias como uma hospitalização. Ou seja, as dificuldades de aprendizagem 
acima aventadas são certamente uma realidade facilmente encontrada entre as crianças e adolescentes internados em hospitais públicos de uma capital do Nordeste, por exemplo. Assim, de acordo com Barros (1999), para alguns contextos sócio-educativos, se faz reforçada a importância do caráter suplementador de uma classe hospitalar.

$\mathrm{O}$ atendimento prestado em uma classe hospitalar é, também, fator que contribui para o enfrentamento do estresse da hospitalização. Esta contribuição é, em parte, alcançada graças ao significado e ao valor simbólico da escola na composição das experiências infantis e juvenis que, então resgatadas apesar da condição de hospitalização, reequilibram o desenvolvimento psíquico daquelas crianças e adolescentes. Um psicanalista brasileiro, discorrendo acerca do impacto do câncer na vida de um adolescente, nos diz:

Caberia aos profissionais de saúde, junto aos professores, preparar o terreno para o retorno à escola e aos amigos. Uma das maiores lesões do câncer é a ruptura da vida escolar. As faltas são inevitáveis nas fases iniciais do tratamento, pela necessidade constante de ir às consultas, pelas diversas reações às cirurgias, às drogas ou à radiação. As faltas são compreensíveis quando o corpo expõe suas marcas: cicatrizes, emagrecimento, deformidades ou queimaduras, ausência de cabelos ou pêlos. A incerteza sobre a acolhida e as limitaçôes impostas pelo cansaço e pela dificuldade de concentração inibem os reencontros. A reintegração ao cotidiano escolar é um dos remédios para a depressão, para o isolamento, para a dependência excessiva dos pais. (Schiller, 2000, p.105-106; grifos meus)

Além disso, sendo as intervenções em classe hospitalar pautadas pelo emprego do elemento lúdico e pontuadas pela possibilidade de manifestaçõos artísticas que exploram a criatividade daquelas crianças, apesar do contexto de marcada adversidade, se reforçam as expectativas de retorno à vida normal. Estes ganhos, por sua vez, podem favorecer a eficácia dos tratamentos médicos empreendidos. A esse respeito, são válidos os achados de um estudo que, investigando os efeitos da alegria, do humor e do riso sobre a saúde psíquica e o bem-estar de crianças hospitalizadas, afirmou:

O grupo-pesquisa apresenta de três a quatro vezes mais alterações que o grupo-controle. A alteração mais presente é a modificação do conteúdo das histórias contadas após a atuação dos palhaços. Observa-se um enriquecimento de conteúdo, enredos positivos ou de final feliz e uma maior expressividade 
de conflitos. Outras alterações importantes foram: aumento no tamanho dos desenhos, maiores usos de cores, mais nitidez e aprimoramento nas formas. Todas essas alteraçôes indicam que, de alguma forma, houve uma expansão dos movimentos da criança e de sua forma de se posicionar diante da hospitalização. (Masetti, 1998, p. 72)

A classe hospitalar configura-se ainda como espaço para o desenvolvimento de programas de educação em saúde, junto a pacientes e acompanhantes, tendo em vista que a referência imediata à doença é elemento motivador para a adoção de comportamentos e atitudes que promovam a saúde. O exemplo das mães dos pacientes, como alvos preferenciais da educação em saúde reprodutiva - com atividades desenvolvidas em torno das metas do planejamento familiar e da orientação sexual - é, neste sentido, ilustrativo do caráter multiplicador do atendimento nas classes hospitalares e do seu potencial sócio-político como promotora da educação para a cidadania. Dada a condição de ociosidade experimentada por algumas mães acompanhando os filhos nos internamentos, a participação nas atividades das classes hospitalares é, por elas mesmas, almejada e requerida. Algumas experiências de incorporação das mães (em períodos mais longos de internação) às atividades das classes hospitalares têm, inclusive, logrado êxitos nas investidas de alfabetização destas mães.

Apesar da reconhecida importância dessa modalidade de atuação, devemos ter em conta que a investida neutralizadora do sofrimento proposta pela classe hospitalar será sempre provisória e paliativa, pois a característica de instituição total, nos termos propostos por Goffman, nunca estará superada em um hospital. Em verdade, se considerarmos que a esta característica se soma a marca perniciosa muito própria das instituições disciplinadoras, conforme descritas por Foucault (1987) quando interpretou sócio-historicamente prisões e escolas, então, haveremos de atentar, inclusive, para o cuidado de evitar impregnar o trabalho do professor da classe hospitalar com aquilo que mais tipicamente identifica o empreendimento educativo: a prescrição de normas, proibições, a "docilização dos corpos" das crianças e outras medidas tidas como necessárias ao processo ensino-aprendizagem.

No Brasil, existe atualmente mais de uma centena de classes hospitalares (Oliveira, Fernandes \& Sousa, 2007). Estas resultam, em sua maioria, de convênios firmados entre secretarias estaduais ou municipais 
de Educação ou da Saúde com hospitais. Podem, ainda, operar a partir das iniciativas de hospitais-escola de instituições públicas de ensino superior, cujos quadros de pessoal prevêem funcionários técnico-administrativos de nível médio e/ou pedagogos para atuarem nas classes hospitalares. Assim, a partir de seleção pública, são criados os quadros de professores hospitalares para a Rede Sarah de Hospitais do Aparelho Locomotor - uma rede de hospitais públicos cujo modelo de gestão não é equivalente àquele do Sistema Único de Saúde. A instituição dessa carreira pode se dar, até mesmo, a partir da cooperação com professores de escolas de formação em Saúde dos estados, sob cujas parcerias hospitais do SUS e hospitais universitários implementam as atividades de classe hospitalar em suas enfermarias pediátricas.

As iniciativas de classe hospitalar se dão à custa da escassez de recursos de variadas ordens, muito própria àquela já comum ao financiamento da educação e da assistência médica de caráter público. Muitas classes hospitalares debatem-se, assim, com a falta de material de consumo ou permanente, como brinquedos, jogos, livros, artigos de papelaria, microcomputadores, televisores, mobiliário, entre outros. Algumas são beneficiadas pela infra-estrutura pré-existente de suporte às atividades psicossociais e de terapia ocupacional ou de voluntariado organizado na forma de ONGs, que empreendem, junto às crianças e adolescentes hospitalizados, atividades de contação de histórias ou de brinquedotecas, por exemplo. Em que pese esse quadro de precariedade para sua sustentação institucional, essa modalidade de atendimento acena com crescimento positivo e a cada dia novos hospitais são identificados como demandantes e/ou beneficiáveis com a implantação de mais uma classe hospitalar.

Para esta ampliação faz-se necessário, na maior parte das vezes, que sejam selecionados, do quadro de professores em serviço nas escolas das prefeituras ou nas escolas dos estados, candidatos que tenham interesse em trabalhar com crianças e adolescentes hospitalizados e que reúnam alguns pré-requisitos básicos: em geral, especialização em educação especial elou experiência de docência no ensino fundamental. A estruturação das classes hospitalares existentes até o momento não tem permitido a manutenção de um banco de reserva de professores, tendo em vista que a adaptação dos mesmos à nova realidade de trabalho resulta em algumas desistências e, por conseguinte, substituições. ${ }^{2}$ 
Em verdade, observa-se que a falta de um treinamento mais consistente que prepare esses professores para o ingresso na realidade hospitalar - esclarecendo suas rotinas, dinâmicas de funcionamento e especificidades dos quadros de adoecimento das crianças - é um fator que concorre negativamente para a permanência ou desempenho satisfatório desses professores. Não obstante o planejamento e a coordenação das atividades dos professores lotados nas classes hospitalares sejam, porventura, supervisionados pelas respectivas secretarias de ensino, nem sempre se alcança a regularidade e a sistematicidade requeridas para o acompanhamento contínuo dos professores já em atividade nos hospitais. Além disso, essa estrutura de capacitação contínua em serviço é, em geral, a mesma que se empenha na seleção recorrente de novos professores, os quais, por sua vez, gerarão mais demandas de treinamento e acompanhamento. Some-se a isso o fato dos coordenadores pedagógicos com formação exclusivamente na área da educação, ainda que muitas vezes da educação especial, dificilmente conseguirem agregar o caráter multidisciplinar dos conhecimentos requeridos para o bom desempenho de um professor que atuará em um contexto de ensino-aprendizagem escolar tão heterodoxo como o de um hospital.

O panorama aqui descrito, além de situar o contexto objetivo de realização da prática pedagógica em questão, permite trazer para a pauta de discussões aquilo que é um dos argumentos centrais deste trabalho: a formação profissional para professores e pedagogos de classes hospitalares requer o reconhecimento e a afirmação de um campo do saber essencialmente multiepistêmico.

Mas, se por um lado não se pode prescindir da importância de uma empreitada multidisciplinar no concurso dos fatores que levarão à capacitação de qualidade desses profissionais, por outro, pode-se até prescindir da sua denominação possível. Alguns autores a têm reafirmado como sendo a perspectiva da Pedagogia Hospitalar descrita por Matos e Mugiatti (2006). Contudo, importa menos o nome que se dê e muito mais a intenção e realização do diálogo entre múltiplos campos do saber. Além disso, esperar que uma possível pedagogia hospitalar seja consolidada como um campo do conhecimento para que estudos e pesquisas ganhem fôlego e ousadia é ignorar possíveis contribuições de muitas outras áreas do saber, estas sim já há muito consagradas, como a Psicologia Hospitalar, a Psicopedagogia, a Educação em Saúde, a Antropologia Médica, a Saúde Pública, a Psicanálise, a Medicina Social e a Terapia 
Ocupacional. É desconsiderar, ainda, que um campo do conhecimento, qualquer que seja, com seus métodos e técnicas, autores, conceitos, livros, periódicos, linhas de pesquisa, eventos científicos, disciplinas curriculares, percorre um trajeto histórico muito próprio, quando nem possui uma denominação precisa, até o seu reconhecimento acadêmico formal. Neste percurso, contam, é claro, a influência de temáticas provocativas que proporcionem a pesquisa e a reflexão e o empenho pioneiro de quem desbrava o campo, mas contam, também, variáveis outras, algumas das quais de natureza política ou mesmo cultural, como o prestígio social das profissóes às quais essa provável disciplina se remeteria. E, nesse caso, a Pedagogia Hospitalar, ou denominação que o valha, parece estar remetida muito mais à Educação do que à Saúde.

\section{O perfil ideal para um professor de classe hospitalar}

Esta digressão, que pareceu distanciar-se um pouco das finalidades aplicadas que este artigo tem, serviu apenas para reafirmar o caráter de convergência de múltiplos campos do saber que é requerido para a efetiva profissionalização e, por que não dizer também, instrumentação para a pesquisa de um professor - pedagogo ou licenciado - que trabalhe em classe hospitalar. Assim, a argumentação em prol do reconhecimento desta multidisciplinaridade se atualiza facilmente a partir da apreciação do elenco de algumas habilidades e competências de um professor, esperadas para atuação em classe hospitalar. São elas:

- capacidade do professor de se adaptar à demanda de uma nova classe hospitalar e justificá-la a partir da apreciação de variáveis como: a freqüência de crianças e adolescentes internados; faixa etária e tempo médio de permanência; avaliação das estruturas física e de atendimento do hospital, presença de área disponível para a realização das atividades lúdicas, pedagógicas, recreativas; densidade de leitos na enfermaria pediátrica e dinâmica da utilização do espaço; rotinas de cuidados e atenção destinados às crianças em tratamento, bem como agenda de horários a estas atividades relacionados; avaliação do perfil epidemiológico da clientela atendida (quanto ao tipo de debilidades clínicas e limitaçôes implicadas pelas doenças sofridas pelos jovens pacientes e quanto à recorrência das internações); levantamento do 
perfil sócio-educacional da clientela atendida: procedência do domicílio da criança, renda familiar e escolaridade dos pais, referência a abandono, repetência ou exclusão escolar sofridas pela criança anteriormente à instalação da morbidade;

- capacidade de, quando implantar uma nova classe hospitalar, apreciar a existência de outras medidas humanizadoras (como presença de brinquedoteca, atuação periódica de recreadores voluntários e presença dos pais como acompanhantes integrais à internação) e integrá-las às atividades correntes de uma classe hospitalar;

- capacidade de, quando na presença, por exemplo, de profissionais do tipo atores clown, sugerir modos criativos e funcionais de explorarem os espaços e as rotinas hospitalares, de modo que esses possam compor harmonicamente os momentos de expressão dramática requeridos em dinâmicas de teatro;

- capacidade de, quando da ocorrência desses momentos, adaptar flexivelmente as atividades de ensino e aprendizagem das crianças e adolescentes hospitalizados ou aquelas atividades terapêuticas destinadas a colaborarem no enfrentamento psíquico da hospitalização;

- capacidade de propor maneiras e materiais alternativos na confecção de jogos e brinquedos;

- capacidade de sugerir modos mais apropriados de diagnosticar as demandas de acompanhamento escolar do paciente, modos que o contemple na integralidade de sua condição humana e indissociabilidade de suas necessidades - física, psíquica, social, de gênero, e de outras variáveis.

Espera-se, ainda, que, no âmbito de suas intervenções junto às crianças hospitalizadas, os professores e/ou pedagogos da classe hospitalar identifiquem perguntas de pesquisa que, por sua vez, os motivem no encaminhamento de investigações futuras e produção de conhecimento. Estas contribuiriam tanto à formação dos professores enquanto pesquisadores, quanto ao incremento do sucesso da prática de classe hospitalar, na medida em que os resultados dessas pesquisas fossem devolvidos às comunidades médica e educativa. As pesquisas, por exemplo, poderiam propor estudos de caso-controle com grupos de crianças 
ou adolescentes atendidos em classe hospitalar e grupos não atendidos, bem como estudos de acompanhamento longitudinal pós-alta das crianças que participaram da classe hospitalar, a serem realizados por meio de contatos com escolas regulares para onde retornaram ou foram inseridos. $\mathrm{Ou}$, ainda, em pesquisas que problematizem os métodos de ensino da classe hospitalar, provocando, por exemplo, os limites de aplicação de ferramentas como a pedagogia de projetos, submetida à heterodoxia extrema de um espaço de aprendizagem de uma enfermaria pediátrica; assim, também, em pesquisas que contrastassem a qualidade multisseriada da classe hospitalar, em comparação com realidades similares neste aspecto, como aquelas encontradas em salas de aula de escolas rurais, de assentamentos rurais, de campos de refugiados e outras.

\section{Preâmbulos no esboço de uma proposta}

Delinear algo como um referencial curricular mínimo para a formação de um professor de classe hospitalar requer, ainda, o necessário entendimento e reafirmação do papel desta modalidade de atenção na perspectiva das açóes integrais de saúde e, portanto, no âmbito das iniciativas de humanização da assistência médico-hospitalar. O Programa Nacional de Humanização do Sistema Único de Saúde propõe um conjunto de ações integradas que visam mudar o padrão de assistência ao usuário nos hospitais públicos do Brasil, melhorando a qualidade e a eficácia dos serviços hoje prestados por estas instituições. Neste sentido, dentre tantas prerrogativas, busca valorizar a dimensão humana e subjetiva, presente em todo ato de assistência à saúde. Assim sendo, medidas como a presença de brinquedoteca, atuação periódica de recreadores voluntários e a presença dos pais como acompanhantes à internação se destacam na especificidade de seus direcionamentos a crianças e adolescentes hospitalizados sendo, muitas vezes, precursores da entrada de professores no ambiente hospitalar.

Logo, conceber o caráter multidisciplinar necessário à formação de um professor de classe hospitalar passa, obrigatoriamente, por aproximálo do conhecimento produzido não só por pediatras, fisioterapeutas, fonoaudiólogos, geneticistas, nutricionistas, terapeutas ocupacionais, psicólogos, assistentes sociais e outros profissionais de saúde ou da área médica, bem como, em igual importância, aproximá-lo dos saberes dos artistas clown, dos artistas plásticos, das contadoras de histórias, dos 
Contribuições da educação profissional em saúde à formação para o trabalho...

musicoterapeutas, recreadores, brinquedistas, sempre que estes, felizmente, dividirem os espaços das enfermarias com os professores.

Nesse sentido, passa, ainda, por instrumentá-los para reconhecer que a prática pedagógica em classe hospitalar pode atender tanto a filiaçóes mais comprometidas com o acompanhamento curricular, quanto a filiaçōes comprometidas "apenas" com o enfrentamento do stress da hospitalização. E que tanto uma quanto outra filiação teórico-prática (ou mesmo novas que se venha a distinguir) são possíveis e não necessariamente excludentes. A adoção estrita por uma ou outra das filiações se fará em função das variáveis próprias à enfermaria pediátrica, na qual se implanta a classe hospitalar (tempo médio de internação dos pacientes, tipos de enfermidades, perfil socioeconômico das famílias, presença de outras medidas humanizadoras do atendimento hospitalar), bem como em função de variáveis relativas às condições de funcionamento e manutenção física e material da classe hospitalar (número de professores, disponibilidade de recursos financeiros). Isto possibilitará ao professor de uma determinada classe hospitalar circunstanciar sua prática pedagógica e a respectiva filiação teórica, de modo que possa refleti-la criticamente, e não apenas reproduzir modelos previa e arbitrariamente orientados.

Feitas as considerações mais amplas e gerais acerca da emergência da capacitação de pedagogos e professores para o trabalho em ambientes hospitalares, o que se segue são recomendações mais diretas e objetivas nesse sentido. Não têm a pretensão de, ao mesmo tempo em que são apresentadas, já apontarem as condições e programas para sua implementação. Cumprem, na verdade, o papel de provocar a discussão, trazendo para o cenário contribuições de outros campos da educação profissional.

\section{A educação profissional em saúde e a formação para a classe hospitalar}

A educação profissional em saúde é tradicionalmente destinada a pensar a formação superior - de médicos, enfermeiros, dentistas ou a formação técnica em nível médio - de auxiliares de enfermagem, de técnicos de consultório dentário e, mais recentemente, de agentes comunitários de saúde. Contudo, para além desta vocação original, ela tem muito a oferecer em termos de proposições de métodos e técnicas de ensino a essa que seria uma clientela em potencial de formação para o setor saúde: os professores de classe hospitalar. 
Se considerarmos especialmente a formação técnica de nível médio, que forma recursos humanos para a área de saúde, tendo como ponto de partida o conhecimento acadêmico prévio relativo apenas à educação básica (por vezes apenas ao ensino fundamental), encontraremos desafios similares entre muitos dos cursos de qualificação promovidos pelas Escolas de Formação Técnica em Saúde do sus e a formação requerida para professores das classes hospitalares. Pois, em ambos os casos, se requerem, dentre outros cuidados, uma facilitação na abordagem dos conteúdos que contemple uma necessária tradução do cientificismo da linguagem biomédica, bem como estratégias didático-metodológicas que incorporem de maneira apropriada as contribuiçôes dos contextos mais imediatos e das realidades vividas pelos sujeitos aprendentes.

São sujeitos que, sendo professores da educação básica (universo do qual emana a grande maioria das candidaturas para o trabalho em classe hospitalar), pouco ou inconsistente conhecimento têm acerca da anatomia e fisiologia do organismo humano, dos ciclos evolutivos de doenças, das características clínicas e nosológicas das principais enfermidades da infância, da distribuição das doenças na população brasileira, dos modos de contágio e de transmissão, da peculiaridade do elemento probabilidade nas doenças genéticas. Possuem estas lacunas de conhecimento ou porque só cursaram o magistério de nível médio, ou porque, mesmo tendo alcançado a formação de nível superior - em pedagogia ou licenciaturas -, poucas ferramentas, dessas passagens pela universidade, puderam apropriar, mesmo quando em suas grades curriculares se faziam constar disciplinas como a Biologia Educacional, a Educação Especial ou a Educação em Saúde. ${ }^{3}$

Àqueles que porventura julgarem dispensáveis tal corpo de conhecimento, basta imaginar como pode ser possível a um professor de classe hospitalar que o mesmo seja capaz de, sem reducionismos simplificadores ou sem a reprodução tecnicista da linguagem médica, esclarecer ao professor da escola de origem da criança aspectos centrais de sua enfermidade: o que exatamente ela tem, como e quando vai melhorar, qual o alcance desta melhora, o que fazer e o que não fazer na escola regular para ajudá-la e qual a justificativa para cada uma destas medidas.

Se considerarmos ainda a importância de um domínio mínimo, por parte de um professor que lecionará em uma enfermaria pediátrica, de temáticas como modelos assistências e sistemas de saúde no Brasil, estrutura e 
funcionamento das instituiçôes de saúde, política de humanização dos sistemas de saúde, constataremos, então, a sua absoluta insuficiência. Pois, mesmo considerando uma formação de qualidade em nível superior, aquelas temáticas não são objetos de tratamento didático em nenhuma das disciplinas das graduações em Pedagogia ou Licenciaturas (salvo situação excepcional em que alunos, visionários de seu futuro profissional, optarem por disciplinas eletivas em outros cursos). Àqueles que porventura julgarem dispensáveis tal corpo de conhecimento, basta imaginar como pode ser possível a um professor de classe hospitalar compreender, incorporar criticamente e adaptar ao seu planejamento semanal de atividades as restriçôes de horários impostas pela rotina de funcionamento da enfermaria; ou, ainda, compreender para si e explicar para acompanhantes as razões da transferência de um paciente para um hospital terciário.

Àqueles que, ainda não satisfeitos com tais contra-argumentações, apontarem o possível papel da equipe multidisciplinar - médicos, psicólogos, enfermeiros - no que se poderia chamar de formação em serviço junto a um professor de classe hospitalar, basta lembrar que a hierarquia das relaçôes de autoridade entre os profissionais de saúde em um hospital nem sempre permite a generosidade da oferta gratuita de ensinamentos, sem que esta se faça revestida por trocas próprias dos jogos tácitos de poder.

Logo, essa comunhão de objetivos e desafios - entre a formação de pessoal de nível médio para a saúde e a formação de professores para classes hospitalares - permite mesmo a proposição de aproximações formais que sistematizem e normalizem essa mais recente investida de educação profissional em educação/saúde. Em que pese o fato de que a clientela-alvo da formação de trabalhadores para o setor saúde não inclua professores das redes municipais ou estaduais, esta proposição de parcerias mais regulares e oficiais é ainda assim justificável.

A possibilidade é dada tendo em vista o disposto em uma resolução da Câmara de Educação Básica, do Conselho Nacional de Educação (CNE/CEB n. 2, de 11 de setembro de 2001), que, ao instituir Diretrizes Nacionais para a Educação Especial na Educação Básica, contemplou a categoria de atendimento classe hospitalar nas açóes pretendidas pelo Ministério da Educação e reafirmou o entendimento de que o desafio para os gestores da saúde na implementação de ações voltadas para a qualificação da força de trabalho deve passar pelo reconhecimento da importância de medidas intersetoriais. 
Art. 13. Os sistemas de ensino, mediante ação integrada com os sistemas de saúde, devem organizar o atendimento educacional especializado a alunos impossibilitados de freqüentar as aulas em razão de tratamento de saúde que implique internação hospitalar, atendimento ambulatorial ou permanência prolongada em domicílio. (Brasil, 2001, p. 10; grifo meu)

Destaca-se, nesse sentido, a iniciativa mesma deflagrada, já há mais de uma década, pela Escola Técnica em Saúde do Hospital das Clínicas de Porto Alegre. ${ }^{4}$ A título de exemplificação do que se propõe, segue um recorte de parte do elenco de tópicos proposto pelo documento do Referencial Curricular para o Curso Técnico de Agente Comunitário de Saúde:

(...) Conhecimentos da anatomia e funcionamento do corpo humano./ Cultura popular e suas relaçóes com o processo educativo./ Processo saúde e doença e seus determinantes e condicionantes./ Condições e risco social: violência, desemprego, infância desprotegida, processos migratórios, analfabetismo, instrução, ausência ou insuficiểncia de infra-estrutura básica./ Indicadores de saúde./ Doenças prevalentes na infância: identificação de sinais de risco, medidas e prevenção, encaminhamento e acompanhamento./ Características da criança na fase escolar: nutrição, detecção de fatores indicativos de baixa acuidade visual e auditiva, problemas posturais, cuidados preventivos à doenças bucais, dermatoses e prevenção de acidentes./ Características físicas, psicológicas e sociais do adolescente: crescimento e desenvolvimento, cuidados preventivos em relação à gravidez precoce, às DST e à AIDS, ao uso de drogas e à violência, redes de apoio familiar e social./ Promoção da saúde: conceito e estratégias./ Medidas de prevenção individual e coletiva das principais doenças transmissíveis e não-transmissíveis./ Doenças de notificação compulsória./ Medidas de monitoramento de enfermidades segundo protocolo de saúde pública./ Doenças transmissíveis e não-transmissíveis: conceitos, sinais, sintomas e fatores de risco./ Cadeia de transmissão de doenças: agentes infecciosos, hospedeiros e mecanismos de transmissão (...). (Brasil, 2004, p. 28-34)

A aproximação que se propôs entre o setor de saúde e o de educação, mais especialmente entre as escolas de formação técnica em Saúde e as unidades gestoras da prática da classe hospitalar (secretarias municipais ou estaduais de Educação e hospitais universitários), foi aqui assinalada na especificidade de desafios comuns que elas compartilham: qualificar e capacitar profissionais sem formação superior no campo da saúde para atuação em ambientes hospitalares, desenvolvendo atividades junto a crianças e adolescentes hospitalizados. 
Contribuições da educação profissional em saúde à formação para o trabalho...

Haveria, ainda, contribuições a serem tomadas de empréstimo, desta vez da educação profissional em saúde em nível superior. Estas viriam, contudo, não a partir de preocupações da ordem dos conteúdos, mas, sim, da ordem dos meios. As maneiras de relacionamento humano presentes nas trocas que se estabelecem no cotidiano do trabalho em um hospital: pessoas, travestidas de colegas em equipe, bem como crianças, adolescentes e mães, travestidos de pacientes internados e acompanhantes. A esse respeito, são oportunas as colocações de Cardoso e Grossman (2006, p. 6):

Nas últimas décadas, a preocupação com a capacitação dos profissionais de saúde é uma realidade. As modificações no perfil de morbi-mortalidade, bem como a avalanche de novas informações, em velocidade jamais vista anteriormente, têm levado a profundas reflexões sobre essa temática. A ênfase da formação médica passou a estar centrada na interpretação de exames cada vez mais complexos e na prescrição de drogas potentes. Entretanto, os pacientes oferecem seus relatos pessoais em troca de cuidado; não estão apenas procurando o manejo de seus sintomas e um lugar seguro para o tratamento, querem, além disso, entender e dar significado às suas próprias histórias.

Assim, visando melhor preparar o pedagogo ou professor da educação básica para o trato com o elemento da subjetividade, quando de sua confrontação com experiência da doença vivida pelas crianças, é que se propõe o que vem a seguir.

O que têm a dizer as "narrativas em medicina" à formação de professores para a classe hospitalar?

O uso das narrativas literárias sobre doenças e sobre a prática médica representa uma ferramenta de ensino-aprendizagem com uso já reconhecido - ainda que não estabelecido em abrangência - para a formação de profissionais de saúde. Parte do princípio de que:

Ao enfocar a atividade de contar histórias e suas múltiplas interpretações como cerne da prática clínica, as narrativas literárias apresentam-se como importantes ensinamentos da arte da comunicação médico-paciente. (Cardoso \& Grosmann, 2006, p. 8)

As narrativas literárias apropriadas para essa finalidade são aqueles filmes, romances, novelas, contos ou crônicas cujas tramas giram em torno 
da descoberta de uma doença, das trajetórias e itinerários em busca de tratamentos, dos dramas experimentados com o anúncio da inexistência de cura, com as revelações inusitadas que se fazem paralelamente à doença, com as interrogações existenciais elaboradas pelos personagens a partir da dor, da perda, da tragédia. Não raras vezes, o sofrimento advindo de uma enfermidade ou o entrelaçamento de histórias de vida provocadas por situaçôes-limite que se cruzam no protagonismo de uma doença tem inspirado escritores, dramaturgos e roteiristas. Clássico da literatura universal, $A$ montanha mágica, de Thomas Mann, é um exemplo paradigmático. Outros exemplos estão em obras de autores brasileiros, como Machado de Assis, em seu o Alienista, ou no cinema, com o Óleo de Lorenzo, que emocionou platéias.

Outras vezes, se perfaz o caminho inverso, quando médicos como Moacir Scliar, notabilizado por profícua produção literária, figuram a doença - individual ou coletivamente situada - em suas histórias. Assim também é ilustrativa a capacidade de Oliver Sacks:

Em seus ensaios, Oliver Sacks transforma intencionalmente os relatos clínicos em artefatos literários, mostrando que somente a forma narrativa - com suas nuances imprevisíveis, seus detalhes dramáticos, os sofrimentos e experiências de personagens singulares - restitui à abstração da doença uma feição humana, desvelando novas realidades para a investigação científica e problematizando os limites entre o físico e o psíquico. (Sacks, 1997, p. 272)

O apropriar-se de narrativas literárias como ferramenta didática na instrução de professores para o trabalho em classes hospitalares pressupõe que a subjetividade dos pacientes - crianças e adolescentes, principalmente - encontra mais espaço de expressão junto a esses professores do que junto aos médicos e enfermeiros. Talvez mais até do que encontraria junto aos psicólogos da equipe, uma vez que o simbolismo da escola, ressignificada no ambiente das enfermarias, provoca naqueles jovens pacientes muitas manifestações sensíveis próprias da infância e da adolescência.

Logo, como resultados dessa investida metodológica de ensino, espera-se, junto aos professores assim capacitados:

- favorecer a construção de suas próprias narrativas em prontuários, bem como favorecer a esses mesmos professores, a interpretação das narrativas de anamneses e relatos clínicos (notórios 
Contribuições da educação profissional em saúde à formação para o trabalho...

pelos tecnicismos) dos demais profissionais da equipe de saúde;

- favorecer a construção de relatos de casos clínicos (da clínica psicopedagógica) relativos aos pacientes sob seus cuidados, relatos esses úteis na troca multidisciplinar do ambiente de aprendizagem contínua de um hospital, ou publicáveis em periódicos científicos;

- favorecer a melhor interpretação das narrativas produzidas pelas crianças (presentes em desenhos, em relatos orais, ou sugeridos em jogos e brincadeiras) nos moldes da escuta pedagógica, descrita por Ceccim (1997);

- favorecer o trabalho com a contação de histórias, principalmente quando esta abordagem junto às crianças hospitalizadas permitir se abster de finalidades de alfabetização e letramento, para então privilegiar a função terapêutica de elaboração catártica dos sentimentos, por parte das crianças. Haverá quem diga que esses mesmos resultados poderiam ser alcançados pelo trabalho junto aos professores, com narrativas literárias de qualquer natureza, não necessariamente médicas ou do universo da doença. No entanto, reafirmo o mérito dessas últimas, pois "A ênfase nas narrativas em medicina parece ser um caminho profícuo para aproximar o [profissional de saúde] do mundo do paciente, a ajudá-lo a entender o que a doença representa para cada indivíduo em particular" (Cardoso \& Grossman, 2006, p. 8).

O uso de narrativas literárias sobre doenças e sobre a prática médica em programas de formação para professores de classe hospitalar espera, por fim, cumprir a finalidade de resgatar, dos próprios professores, suas experiências anteriores com a doença, ofertando-lhes alguma autoridade de fala no processo ensino/aprendizagem que permeia sua formação profissional. Esta preocupação é aconselhável caso não se queira perder de vista a contribuição do conhecimento prévio destes professores, então posicionados como alunos. Isto é possível tendo em vista que o fenômeno do adoecimento é comum às realidades mundanas de todos nós, sendo que, no caso de professores e pedagogos, é uma verdade tanto maior, posto que a grande maioria destes profissionais são mulheres recorte de gênero que as releva, numa perspectiva sócio-antropológica, 
no papel de cuidadoras. Como se não bastasse, além disso, muitas são mães, o que as aproxima ainda mais da experiência da doença na infância.

\section{Considerações finais}

Recapitulando a preocupação de dar voz às experiências pessoais e profissionais das professoras, conforme assinalado, fica, a título de recomendação, o encaminhamento de pesquisas de cunho fenomenológico que retirem dos bastidores as vivências subjetivas, as opiniões, sugestões, expectativas, críticas e anseios destas professoras em relação ao trabalho em classes hospitalares, de sorte que se possa melhor fundamentar qualquer proposta teórico-metodológica de formação para essa modalidade de atendimento. Trabalhos desenvolvidos em outros países, de língua inglesa principalmente (bibliografia, a propósito, muito pouco explorada pela comunidade acadêmica brasileira, preocupada em refletir a classe hospitalar), apontam, por exemplo, que: "The professional adaptation the teacher experiences is a probable research topic as teachers are compelled to became lifelong learners in order to be enpowered to teach in the ambivalent hospital school setting" (Carstens, 2004, p. 86). ${ }^{5}$

A aproximação mais estreita da reflexão acerca da classe hospitalar com a Educação em Saúde não pode prescindir, ainda, de uma filiação organizativa que, dentre outras vantagens, permitiria uma articulação política mais efetiva pela melhora das condiçôes de trabalho desses profissionais. Pois, se os estudos da prevalência de doenças ocupacionais apontam que o segmento dos professores é um daqueles sob grande risco de morbidade, então, os professores de classes hospitalares, certamente, vivem sob condições de potencialização desse risco ocupacional. A filiação organizativa que se sugere poderia ser aquela abaixo recomendada:

Outro espaço interessante de formação e vivência interdisciplinar tem sido a Articulaçăo Nacional de Movimentos e Práticas de Educação Popular em Saúde - ANEPS. Formada por pessoas oriundas de lugares tão díspares quanto a Medicina, a Pedagogia e os Movimentos Sociais, por exemplo, a articulação tem oferecido possibilidades absolutamente inovadoras de formação e atuação, e de formação por meio da atuação. (Buchabqui \& Capp, 2006, p. 35; grifos meus) 
Reconheço, por fim, o caráter introdutório da discussão aqui encaminhada, contentando-me com o fato de que a proposição de um diálogo temático como esse já é sinalizador de mudanças próximas.

\section{Recebido em abril de 2007 e aprovado em outubro de 2007.}

\section{Notas}

1. Neste trabalho se optou pela denominação "classe hospitalar", assim como disseminada pelo MEC (Brasil, 2002), ao mesmo tempo em que se reconhece a legitimidade de outros modos de nomear essa modalidade de atendimento, como, por exemplo, Escolarização Hospitalizada (Matos \& Mugiatti, 2006) ou Escola Hospitalar (Fonseca, 2003). Tal opção foi arbitrária, pautada talvez por certa tradição no uso, mas não tem fundamento ideológico e, portanto, não endossa filiação teórica necessária e exclusiva a nenhuma das possíveis vertentes de estudo da temática. Incorpora, ainda, sob essa mesma rubrica, o atendimento pedagógico domiciliar prestado por Casas de Apoio.

2. Esse cenário de alta rotatividade pode ser apreciado a partir da realidade do trabalho nos hospitais da cidade de Salvador, onde os que ofertam essa modalidade de atendimento - à exceção do Hospital de Reabilitação Sarah e do Hospital da Criança de Irmã Dulce - sofrem continuamente com mudança de professores.

3. Exceção é feita aos egressos de cursos de Licenciatura em Biologia e Licenciatura em Ciências Naturais.

4. O Programa de Apoio Pedagógico (PAP) é um trabalho pioneiro de classe hospitalar em Porto Alegre, desenvolvido em uma parceria entre a Escola Estadual Técnica em Saúde (ETS) e o Hospital de Clínicas da UfRGS desde agosto de 1990. A discussão do projeto originou-se quando a equipe multidisciplinar do Hospital, responsável pelas internações pediátricas, constatou que as crianças com prolongadas e repetidas internaçóes eram prejudicadas ao retornarem às escolas. Isto possibilitou realizar uma ação interinstitucional integrada e, em setembro de 1990, oficializou-se o projeto denominado Programa de Apoio Pedagógico, que antecipou a legislação (Estatuto da Criança e do Adolescente Hospitalizados, Resolução n. 41 de outubro de 1995 - Ministério da Justiça - Brasília, DF), garantindo o direito à escola para a criança internada.

5. A adaptação profissional que a professora experimenta é um provável tópico de pesquisa, uma vez que as professoras são levadas a se tornarem aprendizes por toda a vida, de modo a serem empoderadas para ensinar no espaço ambivalente da escola hospitalar. (Tradução livre).

\section{Referências bibliográficas}

BARROS, A.S.S. A prática pedagógica em uma enfermaria pediátrica: contribuiçóes para a inclusão desse alunado. Revista Brasileira de Educação, Rio de Janeiro, p. 20-27, set./nov. 1999. 
BRASIL. Conselho Nacional de Defesa dos Direitos da Criança e do Adolescente. Resolução n. 41, de outubro de 1995. Diário Oficial da União, Brasília, DF, 17 out. 1995.

BRASIL. Conselho Nacional de Educação. Resolução CNE/CEB n. 2, de 11 de setembro de 2001. Institui as Diretrizes Nacionais para a Educação Especial na Educação Básica. Brasília, DF: MEC/SEESP, 2001.

BRASIL. Ministério da Educação. Secretaria da Educação Especial. Classe hospitalar e atendimento pedagógico domiciliar: estratégias e orientações. Brasília, DF: MEC/SEESP, 2002.

BRASIL. Ministério da Saúde. Referencial curricular para o curso técnico de agente comunitário de saúde: área profissional saúde. Brasília, DF: Ministério da saúde, 2004.

BUCHABQUI, J.A.; CAPP, E. Convivendo com agentes de transformação: a interdisciplinaridade no processo de ensino-aprendizagem em saúde. Revista Brasileira de Educação Médica, Rio de Janeiro, v. 30, n. 1, p. 32-38, jan./abr. 2006.

CARDOSO, M.H.C.A.; GROSSMAN, E. As narrativas em medicina: contribuições à prática clínica e ao ensino médico. Revista Brasileira de Educação Médica, Rio de Janeiro, v. 30, n. 1, p. 6-14, jan./ abr. 2006.

CARSTENS, L.E. Teacher's experience of teaching in a hospital school: research essay magister education. Republic of South Africa: Rand Afrikaans University, Faculty of Education and Nursing, Dec. 2004.

CECCIM, R.B. Criança hospitalizada: a atenção integral como uma escuta à vida. In: Ceccim, R.B.; Carvalho. P.R.A. (Org.). Criança hospitalizada: a atenção integral como escuta à vida. Porto Alegre: Ufrgs, 1997. p. 27-41.

FONSECA, E.S. Atendimento escolar no ambiente hospitalar. São Paulo: Memnon, 2003.

FOUCAULT, M. Vigiar e punir: nascimento da prisão. Petrópolis: Vozes, 1987.

GOFFMAN, E. Manicômios, prisões e conventos. São Paulo: Perspectiva, 2007. 
MASETTI, M. Soluçôes de palhaços: transformações na realidade hospitalar. São Paulo: Palas Athena, 1998.

MATOS, E.L.M.; MUGIATTI, M.M.T.F. Pedagogia hospitalar: a humanização integrando educação e saúde. Petrópolis: Vozes, 2006.

OLIVEIRA, C.; FERNANDES, T.; SOUSA, T. Além da escola: atendimento que inspira cuidados. Pátio Revista Pedagógica, Porto Alegre, v. 11, n. 41, p. 52-55, fev./abr. 2007.

REINER-ROSENBERG, S. O papel das associações para crianças hospitalizadas na França e na Europa. In: Gille-Leitgel, M. (Org.) Boi da cara preta: crianças no hospital. Salvador: EDUFBA; Álgama, 2003. p. 16-45.

SACKS, O. O homem que confundiu sua mulher com um chapéu e outras histórias clínicas. São Paulo: Cia das Letras, 1997.

SCHILLER, P. A vertigem da imortalidade: segredos, doenças. São Paulo: Cia das Letras, 2000. 